\title{
Genetic parameters for methane emission traits in Australian dairy cows
}

\author{
C. M. Richardson, ${ }^{1,2 *}$ ๑) T. T. T. Nguyen, ${ }^{1} \odot$ M. Abdelsayed, ${ }^{3}$ P. J. Moate, ${ }^{4,5}$ ๑ S. R. O. Williams, ${ }^{4}{ }^{\circ}$ \\ T. C. S. Chud, ${ }^{6} \odot$ F. S. Schenkel, ${ }^{6} \odot$ M. E. Goddard, ${ }^{5}$ I. van den Berg, ${ }^{1} \odot$ B. G. Cocks, ${ }^{1,2} \odot$ L. C. Marett, ${ }^{4} \odot$ \\ W. J. Wales, ${ }^{4}$ and J. E. Pryce ${ }^{1,2}$ (D) \\ ${ }^{1}$ Agriculture Victoria Research, AgriBio, Centre for AgriBioscience, Bundoora, Victoria 3083, Australia \\ ${ }^{2}$ School of Applied Systems Biology, La Trobe University, Bundoora, Victoria 3083, Australia \\ ${ }^{3}$ DataGene Ltd., AgriBio, Centre for AgriBioscience, Bundoora, Victoria 3083, Australia \\ ${ }^{4}$ Agriculture Victoria Research, Ellinbank, Victoria 3820, Australia \\ ${ }^{5}$ Centre for Agricultural Innovation, School of Agriculture and Food, Faculty of Veterinary and Agricultural Sciences, University of Melbourne, \\ Parkville, Victoria 3052, Australia \\ ${ }^{6}$ Centre for Genetic Improvement of Livestock, Department of Animal Biosciences, University of Guelph, Guelph, ON, Canada N1G 2W1
}

\begin{abstract}
Methane is a greenhouse gas of high interest to the dairy industry, with $57 \%$ of Australia's dairy emissions attributed to enteric methane. Enteric methane emissions also constitute a loss of approximately $6.5 \%$ of ingested energy. Genetic selection offers a unique mitigation strategy to decrease the methane emissions of dairy cattle, while simultaneously improving their energy efficiency. Breeding objectives should focus on improving the overall sustainability of dairy cattle by reducing methane emissions without negatively affecting important economic traits. Common definitions for methane production, methane yield, and methane intensity are widely accepted, but there is not yet consensus for the most appropriate method to calculate residual methane production, as the different methods have not been compared. In this study, we examined 9 definitions of residual methane production. Records of individual cow methane, dry matter intake (DMI), and energy corrected milk (ECM) were obtained from 379 animals and measured over a 5-d period from 12 batches across 5 yr using the $\mathrm{SF}_{6}$ tracer method and an electronic feed recording system, respectively. The 9 methods of calculating residual methane involved genetic and phenotypic regression of methane production on a combination of DMI and ECM corrected for days in milk, parity, and experimental batch using phenotypes or direct genomic values. As direct genomic values (DGV) for DMI are not routinely evaluated in Australia at this time, DGV for FeedSaved, which is derived from DGV for residual feed intake and estimated breeding value for bodyweight, were used. Heritability estimates were calculated using univariate models, and correla-
\end{abstract}

Received March 19, 2020.

Accepted August 7, 2020.

*Corresponding author: caeli.richardson@agriculture.vic.gov.au tions were estimated using bivariate models corrected for the fixed effects of year-batch, days in milk, and lactation number, and fitted using a genomic relationship matrix. Residual methane production candidate traits had low to moderate heritability $(0.10 \pm 0.09$ to 0.21 $\pm 0.10)$, with residual methane production corrected for ECM being the highest. All definitions of residual methane were highly correlated phenotypically $(>0.87)$ and genetically $(>0.79)$ with one another and moderately to highly with other methane candidate traits $(>0.59)$, with high standard errors. The results suggest that direct selection for a residual methane production trait would result in indirect, favorable improvement in all other methane traits. The high standard errors highlight the importance of expanding data sets by measuring more animals for their methane emissions and DMI, or through exploration of proxy traits and combining data via international collaboration.

Key words: methane emission, selection criterion, environmental impact, residual methane, sustainable agriculture

\section{INTRODUCTION}

The world has warmed by about $0.85^{\circ} \mathrm{C}$ (IPCC, 2013) as greenhouse gases accumulate. When compared with the period between 1986 and 2005, BOM (2015) have modeled that annual average temperatures are projected to increase by 0.6 to $1.3^{\circ} \mathrm{C}$ by 2030 . This may lead to longer times of drought, which is especially damaging to countries such as Australia (BOM, 2015).

Methane has approximately 28 times the global warming potential compared with $\mathrm{CO}_{2}$. Dairy cattle account for $20 \%$ of the global livestock sector's greenhouse gas emissions, and over half of this is from enteric methane emissions (Gerber et al., 2013). In Australia, the dairy industry contributes only $1.8 \%$ to the national emissions inventory through on-farm activities (NGGI, 
2018). The majority of the dairy industry's contribution $(57 \%)$ is due to the production of enteric methane (UNFCCC, 2018). As a byproduct of feed fermentation in the rumen, enteric methane accounts for $89 \%$ of the methane generated by the cow (Broucek, 2014). The long-term sustainability of the dairy industry is dependent on optimizing economic returns and ensuring a social license to operate by minimizing inefficiency and simultaneously increasing environmental consciousness (Cardoso et al., 2016), both of which are results of selecting for reduced methane in dairy cows.

There is increasing pressure being placed on the dairy industry to improve efficiency and increase the sustainability of raising and maintaining cattle for dairy production, despite dairy cattle contributing only a moderate fraction of greenhouse gases emitted by the agriculture sector (Rojas-Downing et al., 2017). During the process of transforming human inedible plant material into energy, 6 to $11 \%$ of the energy in feed is lost as methane emissions (Appuhamy et al., 2016). If methane production can be reduced, the saved feed-energy captured by the animal could potentially be redirected to economically important traits such as milk production, BW gain, or both (Yan et al., 2010; Haque, 2018).

Genetic selection is a permanent, cumulative solution to improve the dairy industry's sustainability with minimal additional cost or labor to farmers, especially compared with alternative methods such as feed additives and vaccinations. Although the magnitude of emissions expected to be reduced by selecting for lowmethane cows appears small, the dairy industry has a social responsibility to reduce its emissions. Methane is a suitable candidate for reduction through genetic selection, with coefficients of genetic variation reported between 0.10 and 0.15 , and heritability estimates ranging from 0.10 to 0.42 in dairy cattle, depending on the methane trait under investigation (de Haas et al., 2011; Pickering et al., 2015; Lassen and Løvendahl, 2016).

Modern breeding objectives in dairy cattle are focused on improving profitability, animal welfare, and environmental impact (Miglior et al., 2017). Although progress has been made in selecting for farmer profit and animal welfare, breeding goals for environmental traits are in their infancy. Indirectly, genetic selection has reduced the environmental impact of dairy cattle through the reduction in rearing periods, resulting from improvements in fertility and survival, and the dilution effect of increased production (Knapp et al., 2014). For the dairy industry, the goal is to improve the overall sustainability of dairy production by reducing methane emissions without negatively affecting economically important traits. This may be achieved by including a methane trait in the national index that is independent of traits currently included in the overall breeding objective, such as residual methane production (RMP).

Residual methane production has been proposed as a possible candidate trait for selection to reduce greenhouse gas emissions from dairy cattle (Manzanilla-Pech et al., 2016; de Haas et al., 2017). Similar to residual feed intake (RFI), RMP is estimated as the difference between the actual and predicted methane output based on a subset of measured phenotypes. In contrast to methane production ( $\mathbf{M e P} ; \mathrm{kg} / \mathrm{d})$, RMP is corrected for traits that highly influence methane outputs. The RMP has statistically favorable properties because it typically uncorrelated with the measured phenotypes used in its calculation and its response to selection may be accurately predicted (de Haas et al., 2017). Ratio traits such as methane yield (MeY) $(\mathrm{kg} / \mathrm{kg}$ of DMI) and methane intensity (MeI; $\mathrm{kg} / \mathrm{kg}$ of output) are undesirable for use in genetic evaluations due to the unexpected responses to selection, as it is unclear which constituent trait drives genetic progress (de Haas et al., 2017).

In beef cattle, RMP is a moderately heritable trait (0.19) and is calculated based on a multiple linear regression of methane production on $\mathrm{ADG}$ and live weight (Manzanilla-Pech et al., 2016; Velazco et al., 2016), which are both traits that highly influence methane production through a relationship to feed intake. Identifying traits to correct for in the definition of RMP in dairy cattle is a challenge, with milk production, BW, and feed intake seeming to have the greatest physiological effect on MeP (de Haas et al., 2017). The RMP traits are generally phenotypically independent of the influential traits they are corrected for; however, unaccounted for genetic interactions may still exist. By correcting for direct genomic values (DGV) of the influential traits, the calculated RMP traits are genetically independent of the influential traits, an attribute favorable for inclusion of the RMP trait in a selection index (VanRaden et al., 2018). To date, the optimal method to calculate RMP has not yet been established.

The objective of this research was to (1) define candidate RMP traits using a combination of genetic and phenotypic corrections for DMI and ECM, (2) estimate and compare the genetic parameters for the RMP candidate traits, and (3) determine the relationships between these RMP and other methane traits (MeP, $\mathrm{MeY}$, and MeI), as well as ECM and DMI.

\section{MATERIALS AND METHODS}

All experiments in the present study were approved and undertaken in accordance with the Australian Code of Practice for the Care and Use of Animals for 
Scientific Purposes (NHMRC, 2013). Approval to proceed was granted by the Agricultural Research and Extension Animal Ethics Committee of the Department of Jobs, Precincts and Regions (DJPR, 475 Mickleham Road, Attwood, Victoria 3049, Australia).

\section{Phenotypes}

Methane and DMI. A total of 1,712 individual cow methane and DMI measurements were obtained from 379 cows measured over a 5 -d period from 12 experimental batches across 5 yr from 2013 to 2017. Each batch consisted of 22 to 36 animals, and no animals were repeated between batches. Cows were located at the Ellinbank SmartFarm (Ellinbank, Victoria, Australia) and milked twice per day. Measurements for $\mathrm{MeP}$ were performed using the $\mathrm{SF}_{6}$ tracer method previously described by Deighton et al. (2014). Individual feed intakes were measured for the 5-d methane measurement period using an electronic feed recording system (Gallagher Animal Management Systems, Hamilton, New Zealand). Records for methane and DMI were averaged to obtain 1 weekly observation per animal for each phenotype to account for day-to-day variation (Moate et al., 2016). Animals were between 68 and 187 DIM at the start of measurement, and across parities 1 to 9 . Methane yield was calculated as the 5-d average $\mathrm{kg}$ of methane per $\mathrm{kg}$ of DMI, and methane intensity as the 5 -d average $\mathrm{kg}$ of methane per $\mathrm{kg}$ of ECM. Daily milk records were available throughout the recording period, with fat and protein percentages obtained through midinfrared spectroscopy. Energy corrected milk $(\mathrm{kg} / \mathrm{d})$ was calculated using Equation 1 (Tyrrell and Reid, 1965) as follows:

$$
\begin{aligned}
& \mathrm{ECM}= \\
& \frac{\text { milk yield }(\mathrm{kg}) \times[376 \times \text { fat }(\%)+209 \times \text { protein }(\%)+948]}{3,138} .
\end{aligned}
$$

In addition to calculating ECM with phenotypes collected as part of the study, we also calculated ECM from DGV so that we could investigate the phenotypic and genetic correction of ECM. Therefore, Equation 1 was adjusted for the use of DGV as follows:

$$
\begin{aligned}
& \mathrm{ECM}= \\
& \left\{\begin{array}{l}
\left(6,861+\mathrm{DGV}_{\text {milk yield }}\right) \\
\times\left[376 \times\left(4.0+\mathrm{DGV}_{\text {fat\% }}\right)+209 \times\left(3.3 \times \mathrm{DGV}_{\text {protein\% }}\right)+948\right]
\end{array}\right\} / 3,138,
\end{aligned}
$$

The DGV for the 379 animals used in this study were estimated as part of the routine genetic evaluation service of DataGene Ltd. (Bundoora, Victoria, Australia) using a data repository that contained 200 million herd test records at the time of this study, and that continues to increase by 2.9 million herd test records annually (Newton et al., 2020). As DataGene does not calculate DGV for ECM as part of the national service, DGV for ECM were calculated using Equation 2, where phenotypic measurements for milk, fat, and protein in Equation 1 were replaced for milk, fat, and protein DGV that were readjusted for the baseline trait means. FeedSaved (FS) is derived from DGV for RFI, and from EBV for BW (Pryce et al., 2015).

Descriptive statistics for phenotypes are presented in Table 1. The distributions of residuals were checked for normality, skewness, and kurtosis, and no outliers were detected. Outliers were defined as observations more than 3 standard deviations away from the mean.

\section{Alternate Definitions of RMP}

The aim of assessing these alternate definitions of RMP was to develop an RMP trait that may be easily incorporated in a breeding program and included in a

\begin{tabular}{|c|c|c|c|c|c|c|}
\hline Trait $^{1}$ & Unit & $\begin{array}{l}\text { No. of } \\
\text { cows }\end{array}$ & Mean & SD & Minimum & Maximum \\
\hline $\mathrm{MeP}$ & g of methane/d & 379 & 469.00 & 81.03 & 230.80 & 753.90 \\
\hline DMI & $\mathrm{kg} / \mathrm{d}$ & 379 & 24.66 & 3.18 & 14.59 & 32.33 \\
\hline $\mathrm{ECM}^{2}$ & $\mathrm{~kg} / \mathrm{d}$ & 379 & 25.73 & 4.08 & 13.50 & 39.34 \\
\hline FS & $\mathrm{kg}$ & 379 & 39.86 & 78.62 & -191.50 & 316.40 \\
\hline
\end{tabular}
national selection index. To achieve this, 9 selection criteria were considered (Table 2). It is often assumed that there is no correlation between a residual trait

Table 1. Descriptive statistics of the data set used in this study

$\overline{{ }^{1} \mathrm{MeP}}=$ methane production; $\mathrm{MeY}=$ methane yield; $\mathrm{MeI}=$ methane intensity; FS = FeedSaved direct genomic value; ECM_BV = ECM direct genomic value.

${ }^{2}$ Calculated using methods of Tyrrell and Reid (1965). 
and the influential traits used in its calculation; however, genetic correlations may still exist. To account for these possible genetic correlations, a correction for the currently available DGV of traits of interest has been proposed (VanRaden et al., 2018). As DGV for DMI are not routinely evaluated in Australia at this time, DGV for FS, the current trait designed to breed for feed efficiency in Australia (Pryce et al., 2015), were used. The FS trait combines the lifetime RFI of the animal, calculated as a weighted average of the calf and lactating cow RFI, and the maintenance energy requirement of the animal estimated through BW (Pryce et al., 2015). Therefore, for individuals with similar milk production EBV, those that save more feed (i.e., that have higher EBV for FS) have lower requirements for feed, predicted using a combination of RFI and BW as a proxy of maintenance.

In total, 9 different definitions of RMP were tested based on a combination of DMI, FS, and ECM corrections. These were:

\section{Correction of Methane for DMI.}

$$
\mathrm{RMP}_{\mathrm{DMI}}=\mathrm{MeP}-\left(\mathrm{b}_{\mathrm{DMI}} \times \mathrm{DMI}\right),
$$

where $\mathrm{RMP}_{\mathrm{DMI}}$ is RMP phenotypically corrected for DMI; MeP is gross methane production ( $\mathrm{g} / \mathrm{d}$ ); DMI is measured in kilograms per day; and $\mathrm{b}_{\mathrm{DMI}}$ is the linear regression coefficient of $\mathrm{MeP}$ on DMI.
2. Correction of Methane for the DGV of FS.

$$
\mathrm{RMP}_{\mathrm{FS}}=\mathrm{MeP}-\left(\mathrm{b}_{\mathrm{FS}} \times \mathrm{FS}\right),
$$

where $\mathrm{RMP}_{\mathrm{FS}}$ is RMP genotypically corrected for FS; $\mathrm{b}_{\mathrm{FS}}$ is the linear regression coefficient of $\mathrm{MeP}$ on FS; and $\mathrm{MeP}$ is as described above.

3. Correction of Methane for DMI and the $D G V$ of $F S$.

$$
\mathrm{RMP}_{\mathrm{DMI} . \mathrm{FS}}=\mathrm{MeP}-\left(\mathrm{b}_{\mathrm{DMI}} \times \mathrm{DMI}+\mathrm{b}_{\mathrm{FS}} \times \mathrm{FS}\right),[5]
$$

where RMP $\mathrm{PMI}_{\text {DIFS }}$ is RMP phenotypically corrected for DMI and genotypically corrected for FS; and MeP, $\mathrm{b}_{\mathrm{DMI}}, \mathrm{DMI}, \mathrm{b}_{\mathrm{FS}}$, and FS are as described above.

4. Correction of Methane for ECM.

$$
\mathrm{RMP}_{\mathrm{pECM}}=\mathrm{MeP}-\left(\mathrm{b}_{\mathrm{pECM}} \times \mathrm{ECM}\right),
$$

where $\mathrm{RMP}_{\mathrm{pECM}}$ is RMP phenotypically corrected for ECM; ECM is measured in kilograms per day; $b_{\mathrm{pECM}}$ is the linear regression coefficient of $\mathrm{MeP}$ on $\mathrm{ECM}$; and $\mathrm{MeP}$ is as described above.

5. Correction of Methane for the DGV of ECM.

\begin{tabular}{|c|c|}
\hline Abbreviation & on \\
\hline 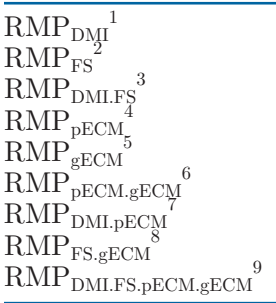 & $\begin{array}{l}=\mathrm{MeP}-\left(b_{\mathrm{DMI}} \times \mathrm{DMI}\right) \\
=\mathrm{MeP}-\left(\mathrm{b}_{\mathrm{FS}} \times \mathrm{FS}\right) \\
=\mathrm{MeP}-\left(\mathrm{b}_{\mathrm{DMI}} \times \mathrm{DMI}+\mathrm{b}_{\mathrm{FS}} \times \mathrm{FS}\right) \\
=\mathrm{MeP}-\left(\mathrm{b}_{\mathrm{pECM}} \times \mathrm{ECM}\right) \\
=\mathrm{MeP}-\left(\mathrm{b}_{\mathrm{gECM}} \times \mathrm{ECM} \_\mathrm{BV}\right) \\
=\mathrm{MeP}-\left(\mathrm{b}_{\mathrm{pECM}} \times \mathrm{ECM}+\mathrm{b}_{\mathrm{gECM}} \times \mathrm{ECM} \_\mathrm{BV}\right) \\
=\mathrm{MeP}-\left(\mathrm{b}_{\mathrm{DMI}} \times \mathrm{DMI}+\mathrm{b}_{\mathrm{pECM}} \times \mathrm{ECM}\right) \\
=\mathrm{MeP}-\left(\mathrm{b}_{\mathrm{FS}} \times \mathrm{FS}+\mathrm{b}_{\mathrm{gECM}} \times \mathrm{ECM} \mathrm{BV}\right) \\
=\mathrm{MeP}-\left(\mathrm{b}_{\mathrm{DMI}} \times \mathrm{DMI}+\mathrm{b}_{\mathrm{pECM}} \times \mathrm{ECM}+\mathrm{b}_{\mathrm{FS}} \times \mathrm{FS}+\mathrm{b}_{\mathrm{gECM}} \times \mathrm{ECM} \_\mathrm{BV}\right)\end{array}$ \\
\hline \multicolumn{2}{|c|}{$\begin{array}{l}{ }^{1} \mathrm{RMP}_{\mathrm{DMI}}=\mathrm{RMP} \text { phenotypically corrected for DMI; } \mathrm{MeP}=\text { gross methane production }(\mathrm{g} / \mathrm{d}) \text {; and } \mathrm{b}_{\mathrm{DMI}}=\text { the } \\
\text { linear regression coefficient of MeP on DMI. }\end{array}$} \\
\hline \multicolumn{2}{|c|}{$\begin{array}{l}{ }^{2} \mathrm{RMP}_{\mathrm{FS}}=\mathrm{RMP} \text { genotypically corrected for } \mathrm{FS} ; \mathrm{FS}=\text { the FeedSaved direct genomic value; } \mathrm{b}_{\mathrm{FS}}=\text { the linear } \\
\text { regression coefficient of MeP on FS. }\end{array}$} \\
\hline \multicolumn{2}{|c|}{${ }^{3} \mathrm{RMP}_{\mathrm{DMI} . \mathrm{FS}}=\mathrm{RMP}$ phenotypically corrected for DMI and genotypically corrected for FS. } \\
\hline \multicolumn{2}{|c|}{$\begin{array}{l}{ }^{4} \mathrm{RMP}_{\mathrm{pECM}}=\mathrm{RMP} \text { phenotypically corrected for } \mathrm{ECM} ; \mathrm{b}_{\mathrm{pECM}}=\text { the linear regression coefficient of } \mathrm{MeP} \text { on } \\
\mathrm{ECM} .\end{array}$} \\
\hline \multicolumn{2}{|c|}{$\begin{array}{l}{ }^{5} \mathrm{RMP}_{\mathrm{gECM}}=\text { residual methane production genotypically corrected for ECM; ECM_BV }=\text { the direct genomic } \\
\text { value of } \mathrm{ECM} ; \mathrm{b}_{\mathrm{gECM}}=\text { the linear regression coefficient of MeP on ECM direct genomic value. }\end{array}$} \\
\hline \multicolumn{2}{|c|}{${ }^{6} \mathrm{RMP}_{\mathrm{pECM} . \mathrm{gECM}}=\mathrm{RMP}$ phenotypically and genotypically corrected for ECM. } \\
\hline \multicolumn{2}{|c|}{${ }^{7} \mathrm{RMP}_{\text {DMI.pECM }}=\mathrm{RMP}$ phenotypically corrected for DMI and ECM. } \\
\hline \multicolumn{2}{|c|}{${ }^{8} \mathrm{RMP}_{\mathrm{FS} . \mathrm{gECM}}=$ residual methane production genotypically corrected for ECM and FS. } \\
\hline \multicolumn{2}{|c|}{$\begin{array}{l}{ }^{2} \mathrm{RMP}_{\text {DMI.FS.pECM.gECM }}=\mathrm{RMP} \text { phenotypically corrected for DMI and ECM and genotypically corrected for ECM } \\
\text { and FS. }\end{array}$} \\
\hline
\end{tabular}

$$
\mathrm{RMP}_{\mathrm{gECM}}=\mathrm{MeP}-\left(\mathrm{b}_{\mathrm{gECM}} \times \mathrm{ECM} \_\mathrm{BV}\right),
$$

Table 2. Definitions of 9 residual methane production (RMP) candidate traits 
where $\mathrm{RMP}_{\mathrm{gECM}}$ is residual methane production genotypically corrected for ECM; ECM_BV is the DGV of $\mathrm{ECM}$; $\mathrm{b}_{\mathrm{gECM}}$ is the linear regression coefficient of MeP on ECM direct genomic value; and $\mathrm{MeP}$ is as described above.

6. Correction of Methane for ECM and the $D G V$ of ECM.

$$
\begin{gathered}
\mathrm{RMP}_{\mathrm{pECM} . \mathrm{gECM}}= \\
\mathrm{MeP}-\left(\mathrm{b}_{\mathrm{pECM}} \times \mathrm{ECM}+\mathrm{b}_{\mathrm{gECM}} \times \mathrm{ECM} \_\mathrm{BV}\right),
\end{gathered}
$$

where $\mathrm{RMP}_{\mathrm{pECM} . \mathrm{gECM}}$ is RMP phenotypically and genotypically corrected for $\mathrm{ECM}$; and $\mathrm{MeP}, \mathrm{b}_{\mathrm{pECM}}$, ECM, $\mathrm{b}_{\mathrm{gECM}}$, and ECM_BV are as described above.

7. Correction of Methane for DMI and ECM.

$$
\begin{gathered}
\mathrm{RMP}_{\text {DMI.ECM }}= \\
\mathrm{MeP}-\left(\mathrm{b}_{\mathrm{DMI}} \times \mathrm{DMI}+\mathrm{b}_{\mathrm{pECM}} \times \mathrm{ECM}\right),
\end{gathered}
$$

where $\mathrm{RMP}_{\mathrm{DMI} \text {.ECM }}$ is RMP phenotypically corrected for DMI and ECM; and MeP, $b_{\mathrm{DMI}}, \mathrm{DMI}, \mathrm{b}_{\mathrm{pECM}}$, and ECM are as described above.

8. Correction of Methane for the DGV of ECM and FS.

$$
\begin{gathered}
\mathrm{RMP}_{\mathrm{FS} . \text { gECM }}= \\
\mathrm{MeP}-\left(\mathrm{b}_{\mathrm{FS}} \times \mathrm{FS}+\mathrm{b}_{\mathrm{gECM}} \times \mathrm{ECM} \_\mathrm{BV}\right),
\end{gathered}
$$

where $\mathrm{RMP}_{\mathrm{FS} . \mathrm{gECM}}$ is residual methane production genotypically corrected for ECM and FS; and MeP, $b_{\mathrm{FS}}$, FS, $b_{\text {gECM }}$, and ECM_BV are as described above.

9. Correction of Methane for ECM, DMI, and the DGV of ECM and FS.

$$
\begin{aligned}
& \mathrm{RMP}_{\text {DMI.FS.pECM.gECM }}=\mathrm{MeP}-\left(\mathrm{b}_{\mathrm{DMI}} \times \mathrm{DMI}+\mathrm{b}_{\mathrm{pECM}}\right. \\
& \left.\times \mathrm{ECM}+\mathrm{b}_{\mathrm{FS}} \times \mathrm{FS}+\mathrm{b}_{\mathrm{gECM}} \times \mathrm{ECM} \_\mathrm{BV}\right), \quad[11]
\end{aligned}
$$

where $\mathrm{RMP}_{\text {DMI.FS.pECM.gECM }}$ is RMP phenotypically corrected for DMI and ECM and genotypically corrected for ECM and FS; and MeP, $b_{\mathrm{DMI}}, \mathrm{DMI}, \mathrm{b}_{\mathrm{pECM}}$, ECM, $\mathrm{b}_{\mathrm{FS}}, \mathrm{FS}, \mathrm{b}_{\mathrm{gECM}}$, and ECM_BV are as described above.

\section{Genomic Analysis}

Genotypes for the 379 animals used in this study were from the routine genomic evaluation system of DataGene Ltd., comprising 47,162 single nucleotide polymorphism markers; the editing procedure used is similar to Erbe et al. (2012). A genomic relationship matrix (G) was constructed following the method of Yang et al. (2010). Principal component analysis of G was performed in $\mathrm{R}$ using the prcomp function in the stats package to confirm that no subpopulations were present in the data set ( $\mathrm{R}$ Core Team, 2013).

\section{Estimating Genetic Parameters}

Univariate and bivariate analysis were performed to estimate genetic parameters using the ASREML 4.1 software program (Gilmour et al., 2015). Genetic parameters were estimated for RMP and associated traits using models that corrected for the fixed effects of lactation number (where lactations numbers were 1,2 , 3 , and $4+$, hence merging all lactations after the third lactation), DIM as the midpoint of the 5 -d test period, and year $\times$ batch interaction. Linear and quadratic effects were tested for DIM, DMI, and ECM. Only the linear effect was significant $(P<0.05)$ for ECM and DMI, with the linear and quadratic effects significant for DIM.

Heritability and variance components were estimated for each trait using the same univariate linear animal model for all traits as follows:

$$
y_{i j k l}=\mu+Y B_{i}+D I M_{j}+D I M^{2}+L N_{k}+g_{l}+e_{i j k l},
$$

where $y_{i j k l}$ is each trait (MeP, MeY, MeI, RMP definitions $1-9, \mathrm{ECM}$ or DMI); $\mu$ is the overall mean; $Y B_{i}$ is the effect of $i$ th year $\times$ batch interaction; $D I M_{j}$ is the linear effect; $D I M^{2}{ }_{j}$ the quadratic effect of $j$ th DIM; $L N_{k}$ is the effect of $k$ th lactation; $g_{l}$ is the random additive genetic effect of lth animal, $g_{l} \sim N\left(0, \mathbf{G} \sigma_{g}^{2}\right)$, where $\mathbf{G}$ is the genomic relationship matrix and $\sigma_{g}^{2}$ is the additive genetic variance; and $e_{i j k l}$ is the random residual effect, $e_{i j k l} \sim N\left(0, \mathbf{I} \sigma_{e}^{2}\right)$, where $\mathbf{I}$ is the identity matrix and $\sigma_{e}^{2}$ is error variance. As all records originated from the same season (spring), we did not include a month or season effect in the model.

Bivariate analyses were performed to estimate genetic and phenotypic correlations between the 9 RMP trait definitions, the 9 RMP traits and other methane candidate traits (MeP, MeY, MeI), and all methane candidate traits and ECM and DMI. The same model as previously described was used to perform the analysis for each pair of traits.

\section{RESULTS}

The aim of this study was to define and compare 9 candidate RMP traits. The defined traits were developed by correcting for traits of influence on $\mathrm{MeP}$ and for compatibility with the national selection index. Therefore, the proposed definitions of RMP are a com- 
bination of phenotypic and genetic corrections for DMI and ECM. The relationship between the 9 RMP trait definitions and other methane candidate traits, ECM, and DMI were then compared for identification of a future selection criterion.

\section{Heritability Estimates}

Genetic parameters for RMP candidate traits are shown in Table 3. Heritability estimates of RMP traits were low to moderate with $\mathrm{RMP}_{\mathrm{FS} \text {.gECM }}$ and $\mathrm{RMP}_{\mathrm{gECM}}$ being the least heritable $(0.11 \pm 0.10)$ and $\mathrm{RMP}_{\mathrm{pECM}}$ being the most heritable trait $(0.21 \pm 0.11)$. Heritability estimates for $\mathrm{RMP}_{\mathrm{DMI}}$, $\mathrm{RMP}_{\mathrm{FS} . \mathrm{DMI}}$, $\mathrm{RMP}_{\text {DMI.pECM}}$, and $\mathrm{RMP}_{\text {DMI.FS.pECM.gECM }}$ were all $0.18 \pm 0.11$, and were 0.15 \pm 0.11 and $0.19 \pm 0.11$ for $\mathrm{RMP}_{\mathrm{FS}}$ and $\mathrm{RMP}_{\mathrm{pECM} . \mathrm{gECM}}$, respectively. Heritability for MeP, MeY, MeI, DMI and ECM was estimated as $0.16 \pm 0.11,0.23 \pm 0.12,0.33 \pm$ $0.12,0.33 \pm 0.13$, and $0.29 \pm 0.13$, respectively.

\section{Genetic Correlations Between RMP Traits}

High phenotypic and genetic correlations were observed between RMP traits (Table 3). The genetic correlations between $\mathrm{RMP}_{\mathrm{DMI}}$ and $\mathrm{RMP}_{\mathrm{FS}}, \mathrm{RMP}_{\mathrm{DMI}}$ and $\mathrm{RMP}_{\mathrm{DMIFS}}$, and $\mathrm{RMP}_{\mathrm{FS}}$ and $\mathrm{RMP}_{\mathrm{DMI} . \mathrm{FS}}$ were $0.77 \pm 0.18,0.99 \pm$ not estimable, and $0.78 \pm 0.18$, respectively. The genetic correlations between traits corrected for ECM was $0.99 \pm 0.09$ between $\mathrm{RMP}_{\mathrm{gECM}}$ and $\mathrm{RMP}_{\mathrm{pECM}}, 0.99 \pm 0.001$ between $\mathrm{RMP}_{\mathrm{pECM}}$ and $\mathrm{RMP}_{\mathrm{pECM.gECM}}$, and $0.99 \pm 0.07$ between $\mathrm{RMP}_{\mathrm{gECM}}$ and $\mathrm{RMP}_{\text {pECM.gECM }}$. High genetic correlations were observed ranging from $0.98 \pm 0.02$ to $0.99 \pm 0.002$ between RM$\mathrm{P}_{\text {DMI.pECM }}, \mathrm{RMP}_{\mathrm{FS} . \mathrm{gECM}}$, and RMP $\mathrm{RMMI.FS.pECM.gECM}_{\text {. }}$

\section{Genetic Correlations Between Phenotypically and Genotypically Corrected Traits}

Genetic correlations between all RMP traits corrected for trait DGV ranged from $0.87 \pm 0.12$ to $0.99 \pm 0.001$ (Table 3). Genetic correlations between traits phenotypically corrected for DMI, ECM, or both ranged from $0.81 \pm 0.12$ to $0.99 \pm 0.001$. The $\mathrm{RMP}_{\text {pECM.gECM }}$ was highly correlated with other traits corrected both phenotypically and genetically, with a genetic correlation with $\mathrm{RMP}_{\text {DMI.FS.pECM.gECM }}$ and RMP $\mathrm{RMMI.FS}_{\text {of }} 0.83 \pm 0.11$ and $0.83 \pm 0.12$, respectively. However, the genetic correlation between $\mathrm{RMP}_{\text {DMI.FS.pECM.gECM }}$ and $\mathrm{RMP}_{\text {DMI.FS }}$ was stronger $(0.99 \pm 0.002)$. Standard errors were not possible to obtain when estimating the genetic correlation between $\mathrm{RMP}_{\mathrm{FS} \text {.DMI }}$ and $\mathrm{RMP}_{\text {DMI.pECM }}$ and the phenotypic correlation between RMP DMI.FS.pECM.gECM $_{\text {. }}$ and $\mathrm{RMP}_{\mathrm{DMI}}$, as these 2 correlations were very close to 1 .

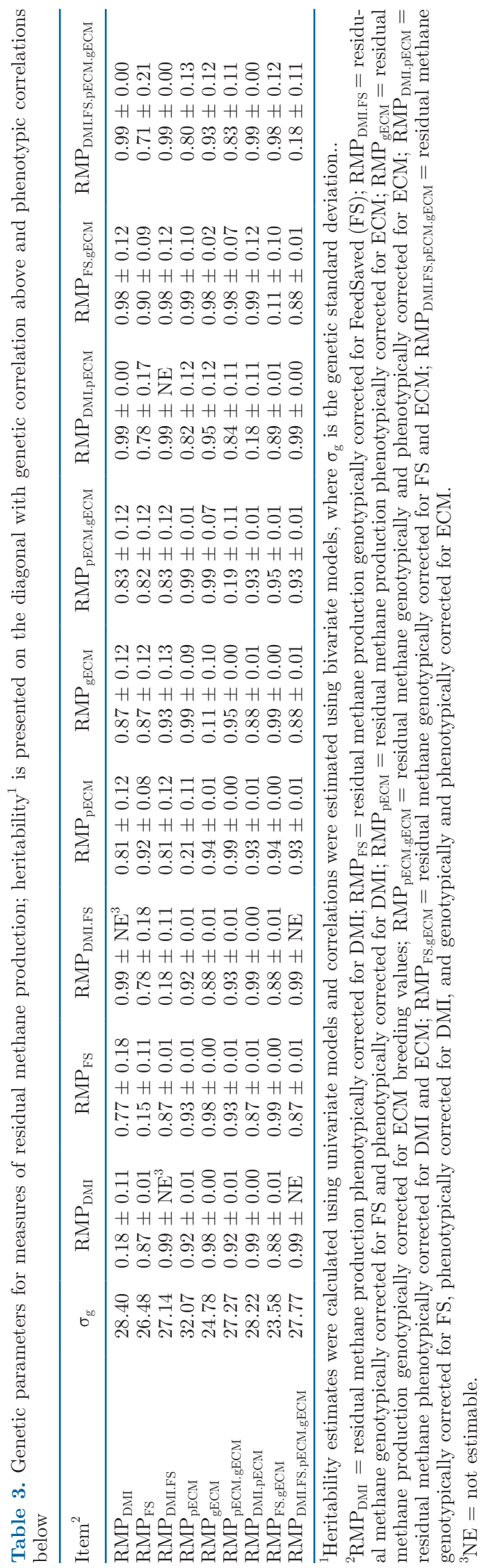


Table 4. Genetic (rg) and phenotypic (rp) correlations between gross methane, methane yield, methane intensity, and residual methane traits; parameters were estimated using bivariate models $^{1}$

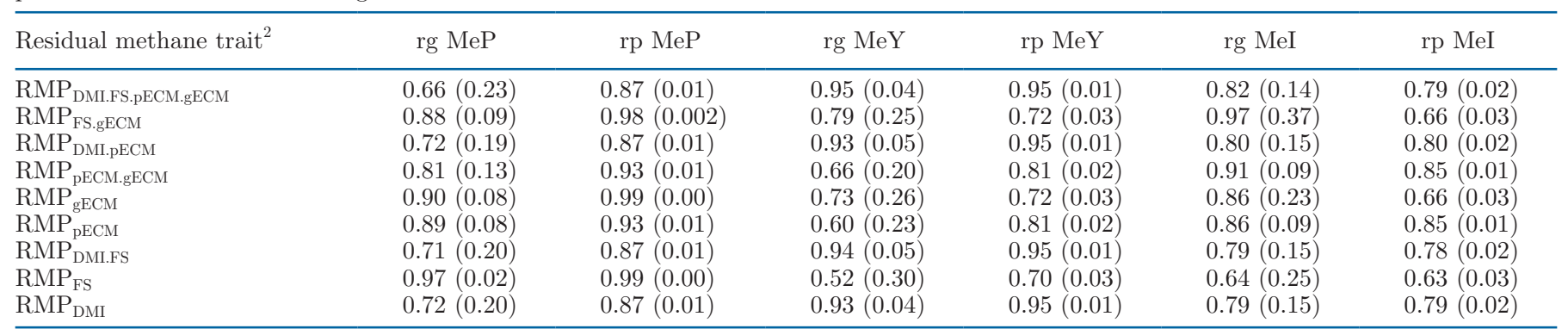

${ }^{1} \mathrm{MeP}=$ methane production; $\mathrm{MeY}=$ methane yield; $\mathrm{MeI}=$ methane intensity.

${ }^{2} \mathrm{RMP}_{\mathrm{DMI}}=$ residual methane production phenotypically corrected for $\mathrm{DMI}$; $\mathrm{RMP}_{\mathrm{FS}}=$ residual methane production genotypically corrected for FeedSaved (FS); $\mathrm{RMP}_{\mathrm{DMI} . \mathrm{FS}}=$ residual methane genotypically corrected for FS and phenotypically corrected for DMI; RMP $\mathrm{pECM}=\mathrm{residual}$ methane production phenotypically corrected for ECM; $\mathrm{RMP}_{\mathrm{gECM}}=$ residual methane production genotypically corrected for ECM breeding values; $\mathrm{RMP}_{\mathrm{pECM} . \mathrm{gECM}}=$ residual methane genotypically and phenotypically corrected for ECM; $\mathrm{RMP}_{\mathrm{DMI} . \mathrm{pECM}}=$ residual methane phenotypically corrected for DMI and ECM; RMP ${ }_{\mathrm{FS} . \mathrm{gECM}}=$ residual methane genotypically corrected for FS and ECM; RMP ${ }_{\text {DMI.FS.pECM.gECM }}=$ residual methane genotypically corrected for FS, phenotypically corrected for DMI, and genotypically and phenotypically corrected for ECM.

\section{Correlations Between Methane Candidate Traits}

The genetic and phenotypic correlation between measures of RMP and MeP, MeY, and MeI were moderate to high $(\geq 0.52 \pm 0.30$ for genetic and $\geq 0.63 \pm 0.03$ for phenotypic correlations, respectively; Table 4). The $\mathrm{MeP}$ had the strongest genetic correlation with $\mathrm{RMP}_{\mathrm{FS}}$ $(0.97 \pm 0.02)$, and the weakest with RMP DMI.FS.pECM.gECM $_{\text {. }}$ $(0.66 \pm 0.23)$. The MeY had the strongest genetic correlation with $\mathrm{RMP}_{\text {DMI.FS.pECM.gECM }}(0.95 \pm 0.04)$ and weakest with $\mathrm{RMP}_{\mathrm{FS}}(0.52 \pm 0.30)$. The MeI had the highest genetic correlation with $\mathrm{RMP}_{\mathrm{FS} . \mathrm{gECM}}(0.97 \pm$ $0.37)$ and, considering standard errors, RMP ${ }_{\mathrm{pECM} . \mathrm{gECM}}$ $(0.91 \pm 0.09)$ and weakest with $\mathrm{RMP}_{\mathrm{FS}}$ of $0.64 \pm 0.25$.

\section{Correlations of Methane Definitions with ECM and DMI}

Genetic Correlations. The only methane candidate trait that had a significant genetic correlation with DMI was MeY $(-0.60 \pm 0.25)$, and with ECM was MeI $(-0.73 \pm 0.18$; Table 5$)$. Standard errors for genetic correlations between methane candidate traits and ECM and DMI were high; therefore, the genetic correlations will not be considered further.

Phenotypic Correlations. The phenotypic correlations between DMI and $\mathrm{MeP}, \mathrm{MeY}$, and $\mathrm{MeI}$ were 0.49 $\pm 0.04,-0.27 \pm 0.05$, and $-0.11 \pm 0.05$, respectively (Table 4 ). The RMP traits that were phenotypically

Table 5. Genetic (rg) and phenotypic (rp) correlations between ECM and DMI with gross methane, methane yield, methane intensity, and residual methane traits; parameters were estimated using bivariate models and standard errors are presented in parentheses

\begin{tabular}{lrrrr}
\hline Trait $^{1}$ & \multicolumn{1}{c}{ rg DMI } & \multicolumn{1}{c}{ rp DMI } & rg ECM & \multicolumn{1}{c}{ rp ECM } \\
\hline MeP & $0.42(0.30)$ & $0.49(0.04)$ & $-0.08(0.39)$ & $0.35(0.05)$ \\
MeY & $-0.60(0.25)$ & $-0.27(0.05)$ & $-0.53(0.33)$ & $-0.17(0.05)$ \\
MeI & $-0.29(0.26)$ & $-0.11(0.05)$ & $-0.73(0.18)$ & $-0.47(0.04)$ \\
RMP $_{\text {DMI }}$ & $-0.29(0.36)$ & $-0.01(0.05)$ & $-0.37(0.41)$ & $0.01(0.05)$ \\
RMP $_{\text {FS }}$ & $0.31(0.35)$ & $0.47(0.04)$ & $-0.05(0.46)$ & $0.34(0.05)$ \\
RMP $_{\text {DMI.FS }}$ & $-0.30(0.36)$ & $-0.01(0.05)$ & $-0.38(0.41)$ & $0.01(0.05)$ \\
RMP $_{\text {pECM }}$ & $0.14(0.34)$ & $0.26(0.05)$ & $-0.50(0.38)$ & $-0.02(0.05)$ \\
RMP $_{\text {gECM }}$ & $0.05(0.46)$ & $0.44(0.04)$ & $-0.41(0.62)$ & $0.30(0.05)$ \\
RMPP $_{\text {pECM.gECM }}$ & $0.01(0.36)$ & $0.26(0.05)$ & $-0.49(0.38)$ & $-0.00(0.05)$ \\
RMPP $_{\text {DMI.pECM }}$ & $-0.29(0.36)$ & $-0.01(-0.05)$ & $-0.38(0.40)$ & $-0.00(0.05)$ \\
RMPP $_{\text {FS.gECM }}$ & $-0.03(0.49)$ & $0.43(0.04)$ & $-0.53(0.70)$ & $0.29(0.04)$ \\
RMP $_{\text {DMI.FS.pECM.gECM }}$ & $-0.36(0.36)$ & $-0.01(0.05)$ & $-0.46(0.41)$ & $-0.00(0.05)$ \\
\hline
\end{tabular}

${ }^{1} \mathrm{MeP}=$ methane production; $\mathrm{MeY}=$ methane yield; $\mathrm{MeI}=$ methane intensity; $\mathrm{RMP}_{\mathrm{DMI}}=$ residual methane production phenotypically corrected for $\mathrm{DMI}$; $\mathrm{RMP}_{\mathrm{FS}}=$ residual methane production genotypically corrected for FeedSaved (FS); $\mathrm{RMP}_{\text {DMI.FS }}=$ residual methane genotypically corrected for FS and phenotypically corrected for DMI; $\mathrm{RMP}_{\mathrm{pECM}}=$ residual methane production phenotypically corrected for ECM; $\mathrm{RMP}_{\mathrm{gECM}}$ $=$ residual methane production genotypically corrected for $\mathrm{ECM}$ breeding values; $\mathrm{RMP}_{\mathrm{pECM.gECM}}=$ residual methane genotypically and phenotypically corrected for ECM; $\mathrm{RMP}_{\mathrm{DMI} . \mathrm{pECM}}=$ residual methane phenotypi-

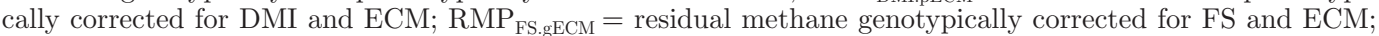
$\mathrm{RMP}_{\text {DMI.FS.pECM.gECM }}=$ residual methane genotypically corrected for FS, phenotypically corrected for DMI, and genotypically and phenotypically corrected for ECM. 
corrected for DMI, RMP ${ }_{\text {DMI }}, \mathrm{RMP}_{\mathrm{DMI}}$ ECM, and RM$\mathrm{P}_{\text {DMI.FS.pECM.gECM, had no significant correlations to }}$ DMI. In contrast, $\mathrm{RMP}_{\mathrm{FS}}$ had a phenotypic correlation of $0.47 \pm 0.04$ with DMI. Energy corrected milk was phenotypically correlated with $\mathrm{MeP}(0.35 \pm 0.05), \mathrm{MeY}$ $(-0.17 \pm 0.05)$, and MeI $(-0.47 \pm 0.04)$. Phenotypic correlations were found between $\mathrm{RMP}_{\mathrm{gECM}}$ and ECM $(0.30 \pm 0.05)$, but were not significant between ECM and $\mathrm{RMP}_{\mathrm{pECM}}, \mathrm{RMP}_{\mathrm{DMI} . \mathrm{pECM}}, \mathrm{RMP}_{\text {DMI.FS.pECM.gECM}}$, and $\mathrm{RMP}_{\mathrm{DMI}}$. All other calculated phenotypic and genotypic correlations between ECM, DMI, and the various RMP traits were not significant $(P>0.05)$.

\section{DISCUSSION}

In this research, we compared 9 methods of calculating RMP traits, adjusting phenotypically and genotypically for influential traits (DMI and ECM). The estimated genetic parameters for the defined RMP traits were then compared for all RMP traits as well as the other methane candidate traits. The overall aim was to identify a candidate methane trait for inclusion in the Australian national breeding program that would reduce the environmental impact of dairy cattle without severely affecting other valuable traits such as production, health, and fertility. The trait should also have the ability to be measured on a large number of individuals and be computationally simple.

\section{Including Methane in Breeding Programs}

As decreasing net emissions may result in a decrease in overall production or general efficiency (Hayes et al., 2013), there is a lack of consensus on management strategies to lower the environmental impact of dairy cattle. However, net emissions will continue to grow proportionally to total dairy production, which is linked to increasing consumer demand for dairy products as the human population increases. Therefore, reducing MeP by reducing milk production is undesirable.

Traditionally, there are many accepted trait definitions to consider for methane when exploring candidate traits for genetic selection, including gross, ratio, and residual. If there is an implied or real economic cost attached to $\mathrm{MeP}$, it might seem simplest to include $\mathrm{MeP}$ in the breeding objective and to publish an EBV for this trait. By considering the economic weights of other traits and the genetic parameters of all traits, an efficient selection index could be derived. However, advising dairy producers to select for a trait (i.e., low $\mathrm{MeP}$ ) that is unfavorably correlated with milk yield might lead to confusion and lack of adoption. Therefore, we have investigated composite traits that could be included in the index without creating this problem.
Ratio traits allow for the consideration of multiple components in a trait definition that is convenient for industry interpretation. However, the application of ratio traits in genetics is contested (Berry and Crowley, 2013) because the complex statistical properties of ratio traits may lead to unfavorable correlations (i.e., MeI may be unfavorably correlated with ECM, which is the denominator of the MeI ratio). In the case of feed efficiency, Kennedy et al. (1993) suggested RFI as a linearization of feed conversion efficiency ( $\mathrm{kg}$ of milk/ $\mathrm{kg}$ of DMI). This process was developed to avoid the use of ratio traits in genetic evaluation, as responses to selection are difficult to predict. In cases when the heritability estimates of the involved traits are similar, it is unclear which constituents of the ratio are being altered by selection pressures (Gunsett, 1984).

The argument for using residuals as a linearization of ratio traits has been deeply reviewed (van der Werf, 2004; Berry and Crowley, 2013; Hurley et al., 2017). There are both benefits and drawbacks, which are dependent on the traits being defined and the desired breeding objective. In the case of methane, a lower environmental impact that does not increase expenses or decrease profitability is required. To demonstrate this, RMP traits were compared with the ratio traits $\mathrm{MeY}$ and MeI.

\section{Defining RMP}

In this research, various definitions of residual methane have been explored in an attempt to identify traits with characteristics and interactions feasible for a potential national methane breeding objective. Our research explored 9 possible definitions of RMP, all of which were found to have genetic parameters within the range of previously recorded traits of similar construct $\left(\mathrm{h}^{2}=0.1-0.3\right.$; Manzanilla-Pech et al., 2016; van Engelen et al., 2018; Breider et al., 2019). Correlations between the RMP traits $(>0.78 \pm 0.18)$ as well as with methane candidate traits $(>0.53 \pm 0.30)$ were favorable; therefore, it is possible that selection for 1 methane trait may lead to indirect progress in all methane candidate traits. All RMP traits are highly genetically correlated $(>0.85)$, suggesting that differences between correction terms were small and that the choice of trait to be included in the breeding objective can be determined on nongenetic aspects (e.g., measurability and practicality of data collection).

Due to these circumstances, $\mathrm{RMP}_{\mathrm{pECM}}$ is proposed as a selection criterion for dairy breeding programs. Although any RMP may be difficult to describe to producers, $\mathrm{RMP}_{\mathrm{pECM}}$ is the most heritable of the RMP traits $(0.21 \pm 0.10)$ and is appealing due to its strong statistical properties and ease of inclusion in a selection 
index. The RMP $\mathrm{PECM}_{\mathrm{p}}$ and MeI capture similar variations with a genetic correlation of $0.86 \pm 0.09$. The benefit of $\mathrm{RMP}_{\mathrm{pECM}}$ is that it may be simply incorporated into an index. Additionally, the genetic correlation between $\mathrm{RMP}_{\mathrm{pECM}}$ and $\mathrm{MeP}$ showed that selecting for $\mathrm{RMP}_{\mathrm{pECM}}$ will reduce net emissions. The $\mathrm{RMP}_{\mathrm{pECM}}$ is superior as its component traits can be easily measured in Australian dairy systems. The ECM is a phenotype that is calculated very simply from data collected routinely in dairy cows from milk production traits, which have high reliabilities (DataGene Ltd., 2018). As a candidate trait, $\mathrm{RMP}_{\mathrm{pECM}}$ is a practical option to be incorporated in an index and have high reliability. The $\mathrm{RMP}_{\mathrm{pECM}}$ fulfills many of the requirements to select for reduced methane emission because it has a negative, favorable genetic correlation with ECM. However, we note the correlation has a large standard error, and thus should be interpreted with caution.

The $\mathrm{SF}_{6}$ method, although laborious, allows for methane measurements to be taken on cows in a pasture setting, and data could be collected on a comparatively large number of individual cows (Moate et al., 2016). On the other hand, collecting DMI data is limited to feed trials that do not represent the commercial farm in pasture-based systems. Currently, collecting DMI records in pasture is not possible on a large number of animals, although technologies are being developed to achieve this (Seymour et al., 2019).

\section{Correcting for Trait Genetic Relationships}

Correcting for the genetic component of DMI using FS did not result in genetic or phenotypic independence of RMP and DMI. However, phenotypically correcting for DMI resulted in an expected phenotypic correlation that was not significantly different from 0 as well as an unchanged genetic correlation. The observed correlations may be due to the use of FS in the genetic correction for feed-based traits, as DGV for DMI are unavailable in Australia. FeedSaved is an EBV for an RFI based trait, where a more negative RFI value is favorable. Although FS is an aggregate trait that considers both lifetime RFI and a maintenance requirement, thereby containing a component of DMI, it cannot fully act as the genetic adjustment for DMI. However, it may be that correcting for DGV does not produce a trait with genetic independence, and instead only increases computational complexity and error. Note that the reliability of RFI was reported to be 0.06 with a standard deviation of 0.07 by Pryce et al. (2015). A lack of genetic independence was also observed in the genotypic and phenotypic correction for ECM. The $\mathrm{RMP}_{\mathrm{pECM}}$ was phenotypically, and not genetically, independent of ECM, and $\mathrm{RMP}_{\mathrm{gECM}}$ was not significantly independent of either. This finding contrasts with the findings of VanRaden et al. (2018), who obtained an RFI trait genetically and phenotypically independent from yield by using genomic predicted transmitting ability for milk net energy and BW. However, a definitive conclusion was not possible due to the large standard errors of the estimated genetic parameters in our study.

\section{Challenges of Small Data Sets}

The small size of the data set available introduced skepticism when estimating genetic parameters and recommending a candidate trait with high confidence. Many of the parameters estimated between methane candidate traits and traits of interests (DMI and ECM) resulted in unreliable parameter estimates with high standard errors. This was a limitation of the small data set and highlights the importance of upscaling through proxy trait development, interbreed evaluations, and international collaboration. In addition to challenges with estimating genetic parameters with a small data set, the size of the data set in combination with the narrow recording windows may have caused confounding of effects in the model. Although each batch contained multiple animals, animals were not represented between batches, which may have led to confounding between batch and animals. The reason for this was to try and maximize the total number of animals with available phenotypes. Mid-infrared spectroscopy has been used to obtain large numbers of predicted methane phenotypes from routine milk samples at herd testing (Vanlierde et al., 2015); however, the viability of using these predicted phenotypes in genomic analysis has yet to be determined.

There is also the opportunity to combine beef and dairy data for genomic prediction of methane with high success in grazing animals (Khansefid et al., 2014). Previously, combining data was challenging, as traits of interest diverged to either meat or dairy production. However, methane may be isolated from this problem because it is strongly related to the breakdown of feed and the digestive capabilities of the animal, rather than the focus of energy partitioning to a specific output. More recently, Williams et al. (2019) showed that VFA proportions in ruminal fluid can be used to predict methane yield, and they suggested that their approach is among the cheapest methods for estimating methane yield of dairy cows. Thus, proxy methane phenotypes related to RMP may be able to be estimated. The most promising opportunity of increasing data set size is through large-scale international initiatives consisting of multiple stakeholders invested in the collation of high-quality feed intake and methane data. However, the variation between international partners in pheno- 
type definitions, measurement techniques, and on-farm management (e.g., diet) is challenging for combining data.

\section{CONCLUSIONS}

This research defined and compared 9 RMP candidate traits. All RMP candidate traits were highly correlated with one another as well as with other methane candidate traits (MeP, MeY, and MeI). Due to this, $\mathrm{RMP}_{\mathrm{ECM}}$ was proposed as the RMP candidate trait for inclusion in routine genetic evaluation based on its heritability and the practicality of obtaining $\mathrm{MeP}$ and ECM measurements on a large number of animals in a pasture-based system. However, the large standard errors associated with some estimated genetic parameters inhibited a definitive conclusion that identified an optimal RMP candidate trait for selection, highlighting the desirability for increasing the data set size. Further research investigating the response to selection of methane candidate traits and the resulting expected decrease in methane emission is required to determine the optimal methane candidate trait in dairy cattle, which may not currently be the most practical.

\section{ACKNOWLEDGMENTS}

We thank DairyBio, jointly funded by Dairy Australia (Melbourne, Australia), The Gardiner Foundation (Melbourne, Australia), and Agriculture Victoria (Melbourne, Australia), for funding this project and C. M. Richardson's PhD project. The authors also thank the staff at Ellinbank SmartFarm (Ellinbank, Australia) for their technical expertise and assistance. The authors have not stated any conflicts of interest.

\section{REFERENCES}

Appuhamy, J. A., J. France, and E. Kebreab. 2016. Models for predicting enteric methane emissions from dairy cows in North America, Europe, and Australia and New Zealand. Glob. Chang. Biol. 22:3039-3056. https://doi.org/10.1111/gcb.13339.

Berry, D. P., and J. J. Crowley. 2013. Cell biology symposium: Genetics of feed efficiency in dairy and beef cattle. J. Anim. Sci. 91:1594-1613. https://doi.org/10.2527/jas.2012-5862.

BOM. 2015. Climate change in Australia: technical report, CSIRO Marine and Atmospheric Research. CSIRO and Bureau of Meteorology (BOM), Aspendale, Australia. Accessed May 2020. https:// www.climatechangeinaustralia.gov.au/media/ccia/2.1.6/cms_page _media/168/CCIA_2015_NRM_TechnicalReport_WEB.pdf.

Breider, I. S., E. Wall, and P. C. Garnsworthy. 2019. Heritability of methane production and genetic correlations with milk yield and body weight in Holstein-Friesian dairy cows. J. Dairy Sci. 102:7277-7281. https://doi.org/10.3168/jds.2018-15909.

Broucek, J. 2014. Production of methane emissions from ruminant husbandry: A review. J. Environ. Prot. (Irvine Calif.) 5:1482-1493. https://doi.org/10.4236/jep.2014.515141.
Cardoso, C. S., M. J. Hötzel, D. M. Weary, J. A. Robbins, and M. A. G. von Keyserlingk. 2016. Imagining the ideal dairy farm. J. Dairy Sci. 99:1663-1671. https://doi.org/10.3168/jds.2015-9925.

DataGene Ltd. 2018. Data Services. Accessed Nov. 2018. https:/ datagene.com.au/DataServicesDataServices.

de Haas, Y., M. Pszczola, H. Soyeurt, E. Wall, and J. Lassen. 2017. Invited review: Phenotypes to genetically reduce greenhouse gas emissions in dairying. J. Dairy Sci. 100:855-870. https://doi.org/ 10.3168/jds.2016-11246.

de Haas, Y., J. J. Windig, M. P. L. Calus, J. Dijkstra, M. de Haan, A. Bannink, and R. F. Veerkamp. 2011. Genetic parameters for predicted methane production and potential for reducing enteric emissions through genomic selection. J. Dairy Sci. 94:6122-6134. https://doi.org/10.3168/jds.2011-4439.

Deighton, M. H., S. R. O. Williams, M. C. Hannah, R. J. Eckard, T. M. Boland, W. J. Wales, and P. J. Moate. 2014. A modified sulphur hexafluoride tracer technique enables accurate determination of enteric methane emissions from ruminants. Anim. Feed Sci. Technol. 197:47-63. https://doi.org/10.1016/j.anifeedsci.2014 .08.003.

Erbe, M., B. J. Hayes, L. K. Matukumalli, S. Goswami, P. J. Bowman, C. M. Reich, B. A. Mason, and M. E. Goddard. 2012. Improving accuracy of genomic predictions within and between dairy cattle breeds with imputed high-density single nucleotide polymorphism panels. J. Dairy Sci. 95:4114-4129. https://doi.org/10.3168/jds .2011-5019.

Gerber, P. J., A. N. Hristov, B. Henderson, H. Makkar, J. Oh, C. Lee, R. Meinen, F. Montes, T. Ott, J. Firkins, A. Rotz, C. Dell, A. T. Adesogan, W. Z. Yang, J. M. Tricarico, E. Kebreab, G. Waghorn, J. Dijkstra, and S. Oosting. 2013. Technical options for the mitigation of direct methane and nitrous oxide emissions from livestock: A review. Animal 7(Suppl. 2):220-234. https://doi.org/10.1017/ S1751731113000876.

Gilmour, A. R., B. J. Gogel, B. R. Cullis, S. J. Welham, and R. Thompson. 2015. ASReml User Guide Release 4.1 Structural Specification. VSN International, Hemel Hempstead, UK.

Gunsett, F. C. 1984. Linear index selection to improve traits defined as ratios. J. Anim. Sci. 59:1185-1193. https://doi.org/10.2527/ jas1984.5951185x

Haque, M. N. 2018. Dietary manipulation: A sustainable way to mitigate methane emissions from ruminants. J. Anim. Sci. Technol. 60:15. https://doi.org/10.1186/s40781-018-0175-7.

Hayes, B. J., H. A. Lewin, and M. E. Goddard. 2013. The future of livestock breeding: Genomic selection for efficiency, reduced emissions intensity, and adaptation. Trends Genet. 29:206-214. https:/ /doi.org/10.1016/j.tig.2012.11.009.

Hurley, A. M., N. López-Villalobos, S. McParland, E. Lewis, E. Kennedy, M. O'Donovan, J. L. Burke, and D. P. Berry. 2017. Genetics of alternative definitions of feed efficiency in grazing lactating dairy cows. J. Dairy Sci. 100:5501-5514. https://doi.org/10.3168/ jds.2016-12314.

IPCC. 2013. Climate Change 2013: The Physical Science Basis. Contribution of Working Group Fifth Assessment Report of the Intergovernmental Panel on Climate Change. Accessed May 2020. http://www.climatechange2013.org/images/report/WG1AR5 Frontmatter_FINAL.pdf.

Kennedy, B. W., J. H. van der Werf, and T. H. Meuwissen. 1993. Genetic and statistical properties of residual feed intake. J. Anim. Sci. 71:3239-3250. https://doi.org/10.2527/1993.71123239x.

Khansefid, M., J. E. Pryce, S. Bolormaa, S. P. Miller, Z. Wang, C. Li, and M. E. Goddard. 2014. Estimation of genomic breeding values for residual feed intake in a multibreed cattle population. J. Anim. Sci. 92:3270-3283. https://doi.org/10.2527/jas.2014-7375.

Knapp, J. R., G. L. Laur, P. A. Vadas, W. P. Weiss, and J. M. Tricarico. 2014. Invited review: Enteric methane in dairy cattle production: Quantifying the opportunities and impact of reducing emissions. J. Dairy Sci. 97:3231-3261. https://doi.org/10.3168/jds .2013-7234.

Lassen, J., and P. Løvendahl. 2016. Heritability estimates for enteric methane emissions from Holstein cattle measured using nonin- 
vasive methods. J. Dairy Sci. 99:1959-1967. https://doi.org/10 $.3168 /$ jds.2015-10012.

Manzanilla-Pech, C. I. V., Y. De Haas, B. J. Hayes, R. F. Veerkamp, M. Khansefid, K. A. Donoghue, P. F. Arthur, and J. E. Pryce. 2016. Genomewide association study of methane emissions in Angus beef cattle with validation in dairy cattle. J. Anim. Sci. 94:4151-4166. https://doi.org/10.2527/jas.2016-0431.

Miglior, F., A. Fleming, F. Malchiodi, L. F. Brito, P. Martin, and C. F. Baes. 2017. A 100-year review: Identification and genetic selection of economically important traits in dairy cattle. J. Dairy Sci. 100:10251-10271. https://doi.org/10.3168/jds.2017-12968.

Moate, P. J., M. H. Deighton, S. R. O. Williams, J. E. Pryce, B. J. Hayes, J. L. Jacobs, R. J. Eckard, M. C. Hannah, and W. J. Wales. 2016. Reducing the carbon footprint of Australian milk production by mitigation of enteric methane emissions. Anim. Prod. Sci. 56:1017-1034. https://doi.org/10.1071/AN15222.

NGGI (National Greenhouse Gas Inventory). 2018. National Greenhouse Gas Inventory UNFCCC classifications. Accessed Nov. 2019. https://ageis.climatechange.gov.au/NGGI.aspx.

Newton, J. E., R. Nettle, and J. E. Pryce. 2020. Farming smarter with big data: Insights from the case of Australia's national dairy herd milk recording scheme. Agric. Syst. 181:102811. https://doi.org/10 .1016/j.agsy.2020.102811.

NHMRC (National Health and Medical Research Council). 2013. Australian code for the care and use of animals for scientific purposes. 8th ed. NHMRC Publications, Canberra, Australia.

Pickering, N. K., M. G. G. Chagunda, G. Banos, R. Mrode, J. C. McEwan, and E. Wall. 2015. Genetic parameters for predicted methane production and laser methane detector measurements. J. Anim. Sci. 93:11-20. https://doi.org/10.2527/jas.2014-8302.

Pryce, J. E., O. Gonzalez-Recio, G. Nieuwhof, W. J. Wales, M. P. Coffey, B. J. Hayes, and M. E. Goddard. 2015. Hot topic: Definition and implementation of a breeding value for feed efficiency in dairy cows. J. Dairy Sci. 98:7340-7350. https://doi.org/10.3168/ jds.2015-9621.

R Core Team. 2013. R: A Language and Environment for Statistical Computing. R Foundation for Statistical Computing, Vienna, Austria.

Rojas-Downing, M. M., A. P. Nejadhashemi, T. Harrigan, and S. A. Woznicki. 2017. Climate change and livestock: Impacts, adaptations, and mitigation. Clim. Risk Manage. 16:145-163. https://doi .org/10.1016/j.crm.2017.02.001.

Seymour, D. J., A. Cánovas, C. F. Baes, T. C. S. Chud, V. R. Osborne, J. P. Cant, L. F. Brito, B. Gredler-Grandl, R. Finocchiaro, R. F. Veerkamp, Y. de Haas, and F. Miglior. 2019. Invited review: Determination of large-scale individual dry matter intake phenotypes in dairy cattle: A systematic review. J. Dairy Sci. 102:7655-7663. https://doi.org/10.3168/jds.2019-16454.

Tyrrell, H. F., and J. T. Reid. 1965. Prediction of the energy value of cow's milk. J. Dairy Sci. 48:1215-1223. https://doi.org/10.3168/ jds.S0022-0302(65)88430-2.

United Nations Framework Convention on Climate Change (UNFCCC). 2018. National Inventory Submissions 2018. Accessed Nov.
2019. https://unfccc.int/process-and-meetings/transparency-and -reporting/reporting-and-review-under-the-convention/greenhouse -gas-inventories-annex-i-parties/national-inventory-submissions -2018 .

van der Werf, J. H. J. 2004. Is it useful to define residual feed intake as a trait in animal breeding programs? Aust. J. Exp. Agric. 44:405-409. https://doi.org/10.1071/EA02105.

van Engelen, S., H. Bovenhuis, P. P. J. van der Tol, and M. H. P. W. Visker. 2018. Genetic background of methane emissions by Dutch Holstein Friesian cows measured by infrared sensors in automatic milking system. J. Dairy Sci. 101:2226-2234. https://doi.org/10 $.3168 /$ jds.2017-13441.

Vanlierde, A., M. L. Vanrobays, F. Dehareng, E. Froidmont, H. Soyeurt, S. McParland, E. Lewis, M. H. Deighton, F. Grandl, M. Kreuzer, B. Gredler, P. Dardenne, and N. Gengler. 2015. Hot topic: Innovative lactation-stage-dependent prediction of methane emissions from milk mid-infrared spectra. J. Dairy Sci. 98:57405747. https://doi.org/10.3168/jds.2014-8436.

VanRaden, P. M., J. R. O'Connell, E. E. Connor, M. J. Vandehaar, R. J. Tempelman, and K. A. Weigel. 2018. Including feed intake data from U.S. Holsteins in genomic prediction. Page 125 in Proc. 11th World Congress on Genetics Applied to Livestock Production, Vol. Biology-Feed Intake and Efficiency 1. World Congress on Genetics Applied to Livestock Production, Auckland, New Zealand.

Williams, S. R. O., M. C. Hannah, J. L. Jacobs, W. J. Wales, and P. J. Moate. 2019. Volatile fatty acids in ruminal fluid can be used to predict methane yield of dairy cows. Animals (Basel) 9:1006. https://doi.org/10.3390/ani9121006.

Yan, T., C. S. Mayne, F. G. Gordon, M. G. Porter, R. E. Agnew, D. C. Patterson, C. P. Ferris, and D. J. Kilpatrick. 2010. Mitigation of enteric methane emissions through improving efficiency of energy utilization and productivity in lactating dairy cows. J. Dairy Sci. 93:2630-2638. https://doi.org/10.3168/jds.2009-2929.

Yang, J., B. Benyamin, N. P. McEvoy, S. Gordon, A. K. Henders, D. R. Nyholt, P. A. Madden, A. C. Heath, N. G. Martin, G. W. Montgomery, M. E. Goddard, and P. M. Visscher. 2010. Common SNPs explain a large proportion of the heritability for human height. Nat. Genet. 42:565-569. https://doi.org/10.1038/ng.608.

\section{ORCIDS}

C. M. Richardson (๑) https://orcid.org/0000-0003-4286-4969

T. T. T. Nguyen @ https://orcid.org/0000-0002-9880-6859

P. J. Moate (๑) https://orcid.org/0000-0003-4598-2047

S. R. O. Williams () https://orcid.org/0000-0003-1321-6487

T. C. S. Chud ๑ https://orcid.org/0000-0001-7559-1165

F. S. Schenkel ๑ https://orcid.org/0000-0001-8700-0633

I. van den Berg (ํ) https://orcid.org/0000-0002-9292-8636

B. G. Cocks @ https://orcid.org/0000-0001-9776-1508

L. C. Marett @ https://orcid.org/0000-0001-9698-8401

J. E. Pryce (ำ https://orcid.org/0000-0002-1397-1282 